\title{
Interferon- $\gamma$ downregulates Hsp27 expression and suppresses the negative regulation of cell death in oral squamous cell carcinoma lines
}

\author{
N Yonekura ${ }^{1}$, S Yokota ${ }^{2}$, K Yonekura ${ }^{3}$, H Dehari ${ }^{1}$, S Arata ${ }^{4}$, \\ G Kohama ${ }^{1}$ and N Fujii ${ }^{*, 2}$ \\ ${ }^{1}$ Department of Oral Surgery, Sapporo Medical University School of Medicine, \\ Sapporo, Japan \\ 2 Department of Microbiology, Sapporo Medical University School of Medicine, \\ Sapporo, Japan \\ ${ }^{3}$ Department of Neurology, Sapporo Medical University School of Medicine, \\ Sapporo, Japan \\ ${ }^{4}$ Center for Biotechnology, Showa University, Tokyo, Japan \\ * Corresponding author: N Fujii, Department of Microbiology, Sapporo Medical \\ University School of Medicine, South-1, West-17, Chuo-ku, Sapporo 060- \\ 8556, Japan. Tel: +81-11-611-2111; Fax: +81-11-612-5861. \\ E-mail: fuji @sapmed.ac.jp
}

Received 10.7.02; revised 12.9.02; accepted 17.10.02

Edited by Y. Kuchino

\begin{abstract}
Interferon- $\gamma$ (IFN- $\gamma$ ) induced cell death in five oral squamous cell carcinoma (SCC) lines. Cell death was specific to IFN- $\gamma$ treatment and did not occur with either IFN- $\alpha$ or TNF- $\alpha$. IFN- $\gamma$ did not induce typical apoptotic phenotype in cells , such as morphological changes and DNA ladder formation. Caspase-3 was partially activated by IFN- $\gamma$. Protein levels of molecular chaperones were examined in cells treated with IFN- $\gamma$. Among these, levels of heat shock protein 27 (Hsp27) were specifically reduced upon IFN- $\gamma$ treatment of oral SCC cells. Recombinant clones overexpressing Hsp27 were more resistant to IFN- $\gamma$-induced cell death than parent cells. Conversely, cells expressing a dominant-negative mutant of Hsp27, in which three serine residues $(15,78$ and 82) were replaced by glycine, were hypersensitive to the effects of IFN$\gamma$ and exhibited a typical apoptotic phenotype. Pretreatment of cells with IFN- $\gamma$ enhanced apoptotic cell death induced by cisplatin. Our data suggest that IFN- $\gamma$ suppresses Hsp27 expression in oral SCC cells and blocks the inhibitory effects of this molecular chaperone on apoptotic cell death. Moreover, IFN- $\gamma$ initiates the transition of oral SCC cells to the proapoptotic and/or aborted apoptotic state. Hsp27 plays a crucial role in the inhibition of apoptosis of oral SCC cells. Our findings highlight the importance of employing IFN- $\gamma$ in combination with certain anticancer drugs as treatments for oral cancer. We suggest that Hsp27 plays a significant role in the IFN- $\gamma$-induced sensitization of oral SCC cells to anticancer drugs.

Cell Death and Differentiation (2003) 10, 313-322. doi:10.1038/ sj.cdd.4401169
\end{abstract}

Keywords: oral squamous cell carcinoma; interferon- $\gamma$; Hsp27; molecular chaperone; cisplatin

Abbreviations: HSP, heat shock proteins; Hsp27, $27 \mathrm{kDa}$ heat shock protein; Hsp27-Gly, mutant Hsp27, three serine residues are substituted with glycine residues; Hsp70, $72 \mathrm{kDa}$ heat shock protein; IFN, interferon; SCC, squamous cell carcinoma; TNF, tumor necrosis factor

\section{Introduction}

Interferon- $\gamma($ IFN $-\gamma)$ is considered a likely candidate for combination therapy in anticancer drug regimes. For example, IFN- $\gamma$ enhances the cytotoxicity of cisplatin, a widely used potent anticancer drug, ${ }^{1}$ against human ovarian cancer cell lines. ${ }^{2}$ Our group is interested in the molecular mechanism of synergism between anticancer drugs and IFN- $\gamma$. IFNs either induce or enhance apoptosis because of inhibition of protein synthesis, which occurs through the activation of both the dsRNA-activated protein kinase (PKR) and the 2', 5'oligoadenylate synthetase/ribonuclease $\mathrm{L}$ system. ${ }^{3-6} \mathrm{Re}-$ cently, we reported the augmentation of Verotoxin-induced apoptosis in oral squamous cell carcinoma (SCC) lines treated with IFNs, in particular IFN $-\gamma^{7}$ Although oral SCC cells underwent cell death when treated with IFN- $\gamma$ alone, typical apoptotic phenotypes, such as DNA ladder formation, were not observed. In this report, we focus on elucidating the role of molecular chaperones in IFN- $\gamma$-induced cell death and augmentation of apoptosis in oral SCC cells. Molecular chaperones are ubiquitous and highly conserved proteins, which participate in protein folding, assembly, transport to particular subcellular compartments and degradation. ${ }^{8}$ Most chaperones are induced when cells are exposed to stressful conditions such as heat, chemical agents, accumulated denatured proteins and reactive oxygen species. Molecular chaperones are also known as heat shock proteins (HSP) or stress proteins. Generally, high levels of HSP are found in various types of tumors suggesting a possible role for chaperones in tumor cell survival and malignancy. ${ }^{9-11}$ Molecular chaperones act as survival proteins. A number of studies indicate that HSP, such as Hsp70 and Hsp27, inhibits the apoptotic signaling pathway at various points (reviewed in Creagh et al., ${ }^{9}$ Samali and Orrenius, ${ }^{12}$ and Xanthoudakis and Nicholson ${ }^{13}$ ). Here, we describe a novel downregulation of $\mathrm{Hsp} 27$ expression in response to IFN- $\gamma$ treatment of oral SCC cells. Hsp27 possibly contributes to promoting the proapoptotic state and/or aborted apoptosis ${ }^{14}$ in these oral SCC cells. 


\section{Results}

\section{Effects of IFN- $\alpha$, IFN- $\gamma$ and TNF- $\alpha$ on SCC cell viability}

Changes in cell viability upon treatment with IFN- $\alpha$, IFN- $\gamma$ or TNF- $\alpha$ were determined using the formazan-formation assay (Figure 1). Closely similar results were observed by other assay systems, such as trypan blue dye exclusion and gentian violet staining (data not shown). While IFN- $\gamma$ dramatically reduced oral SCC cell viability, this had no effect on the cervix adenocarcinoma cell, HeLa. IFN- $\alpha$ had less effect on oral SCC cell viability and TNF- $\alpha$ had no effect at all. After 24 or $48 \mathrm{~h}$ of IFN- $\gamma$ treatment, a significant level of cell death was observed (Figure 1). The time required by IFN- $\gamma$ to induce cell death was determined. As shown in Figure 2, observed levels of cell death with $4 \mathrm{~h}$ exposure of IFN- $\gamma$ were similar to those of overexposure times. Therefore initiation of cell death signal probably completes within the first few hours of exposure to IFN- $\gamma$.

IFN- $\gamma$-induced cell death did not result in typical apoptotic phenotypes, such as DNA fragmentation (Figure 3) and morphological changes. Figure 4 displays data of electron microscopic observation. Some of the OSC70 cells treated with IFN- $\gamma$ showed morphology similar to that of untreated cells as control, and the others had marginal chromatin condensation in the nuclei, to a slight extent, but neither cap formation nor nuclear fragmentation as typical apoptotic figures were recognized. In addition, there were occasional cells with abundant lysosomes containing electron dense granules in the cytoplasm, suggesting any cytotoxic change of tumor cell due to the treatment of IFN- $\gamma$. However, these cells had intact cell membranes and many microvilli, showing no necrotic characteristic but rather live contact with neighboring cells. These results indicate that IFN- $\gamma$-induced cell death is not representative of typical apoptosis. To further characterize the IFN- $\gamma$-induced cell death, we determined the activation of caspase-3, an effector caspase of apoptosis that is proteo-
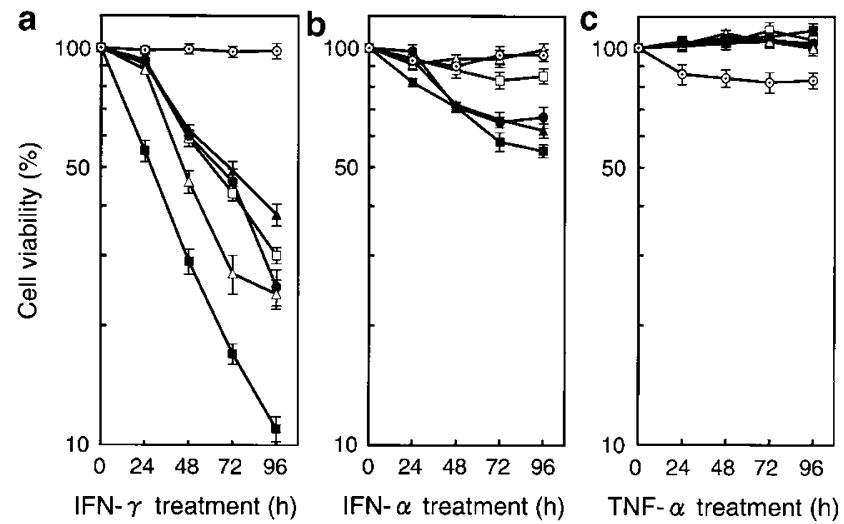

IFN- $\gamma$ treatment $(h)$

IFN- $\alpha$ treatment $(\mathrm{h})$

TNF- $\alpha$ treatment $(h)$

Figure 1 IFN- $\gamma$, but neither IFN- $\alpha$ nor TNF- $\alpha$, induces cell death in oral SCC cells. SCC cell lines [OSC70 ( $\mathbf{\square}), \operatorname{OSC19}(\square), \operatorname{OSC20}(\boldsymbol{O}), \operatorname{OSC} 30(\mathbf{\Lambda})$ and OSC40 $(\triangle)$ ] and HeLa cells $(\odot)$ were cultured in the presence of $1000 \mathrm{lU} / \mathrm{ml}$ of IFN- $\gamma$ (a), $1000 \mathrm{IU} / \mathrm{ml}$ of IFN- $\alpha$ (b) or $10 \mathrm{ng} / \mathrm{ml}$ of TNF- $\alpha$ (c). Cell viability of the treated cells was determined by the formazan-formation assay in triplicate, and is expressed as relative values (mean \pm S.D.) to nontreated control

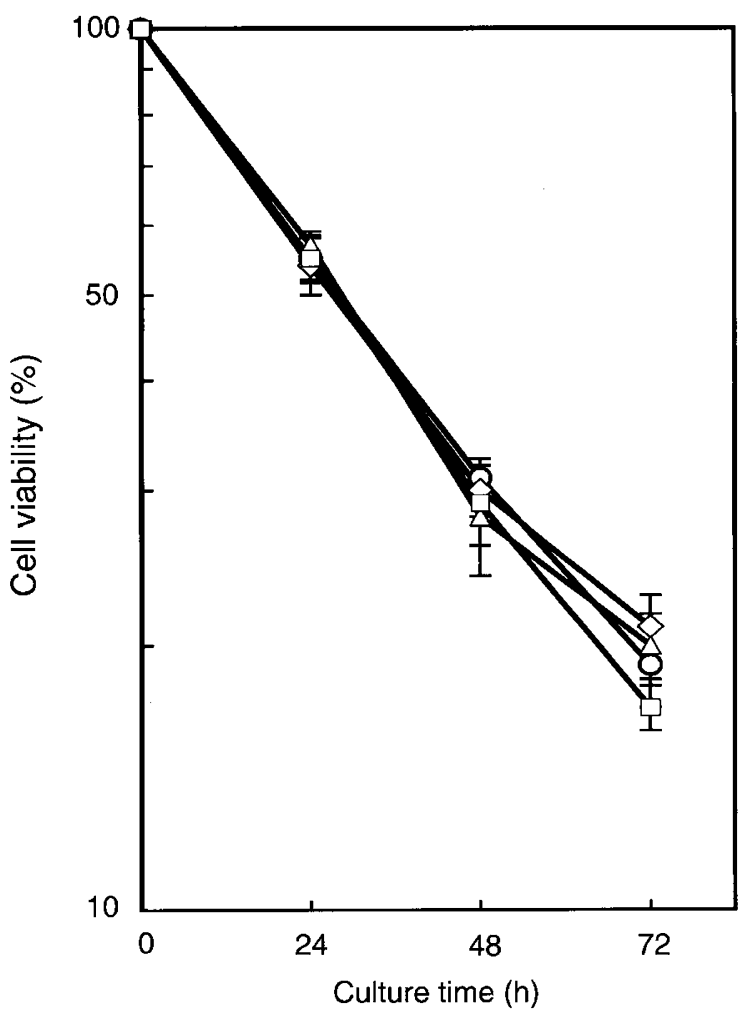

Figure 2 Time dependency for induction of cell death to IFN- $\gamma$ exposure. OSC70 cells were cultured in the presence of $1000 \mathrm{IU} / \mathrm{ml} \mathrm{IFN}-\gamma$ for initial $4 \mathrm{~h}(\mathrm{O})$, $12 \mathrm{~h}(\diamond) 24 \mathrm{~h}(\triangle)$ and $72 \mathrm{~h}(\square)$, and then in normal medium. Cell viability of the treated cells was determined by the formazan-formation assay at 24, 48 and $72 \mathrm{~h}$ in triplicate. The results are expressed as relative values (mean \pm S.D.) to nontreated control
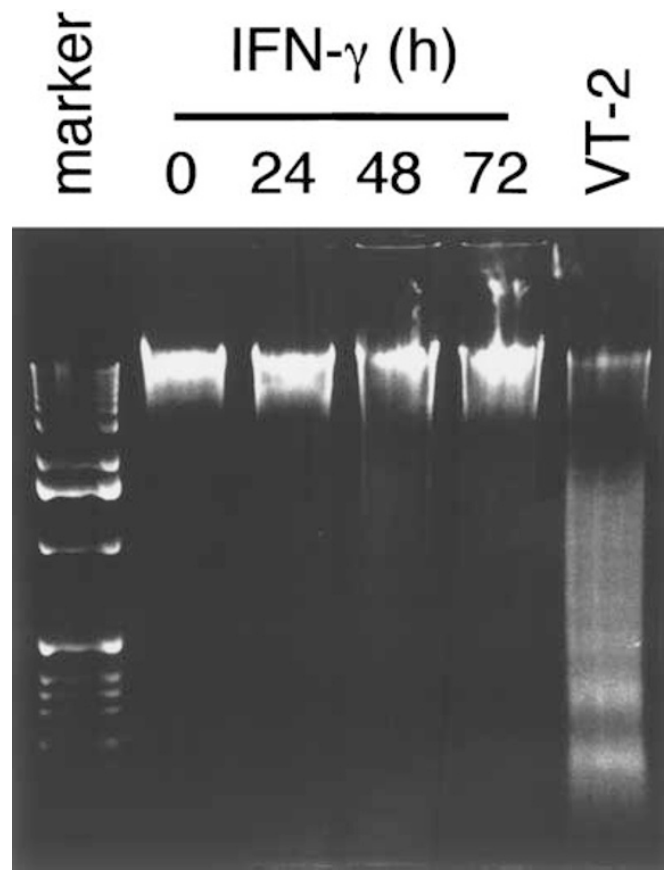

Figure 3 IFN- $\gamma$-induced cell death does not show DNA fragmentation. OSC70

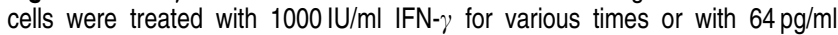
Verotoxin-2 (VT-2) for $48 \mathrm{~h}$ as a control experiment for apoptotic cell death. The extracted DNA was applied to electrophoresis on a 1.5\% agarose gel and stained with ethidium bromide 


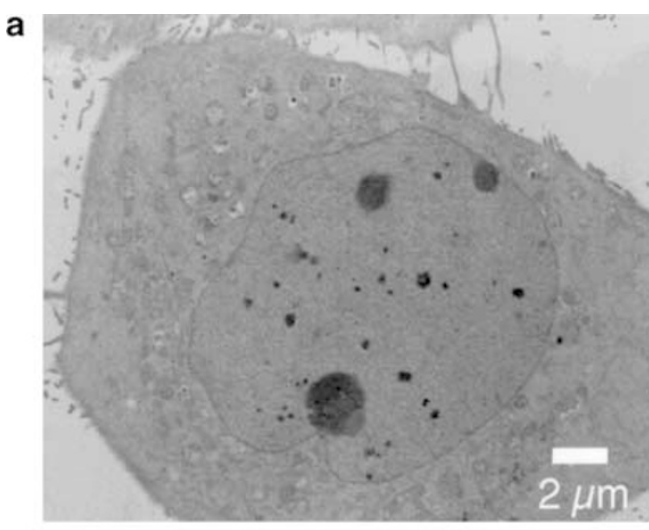

b

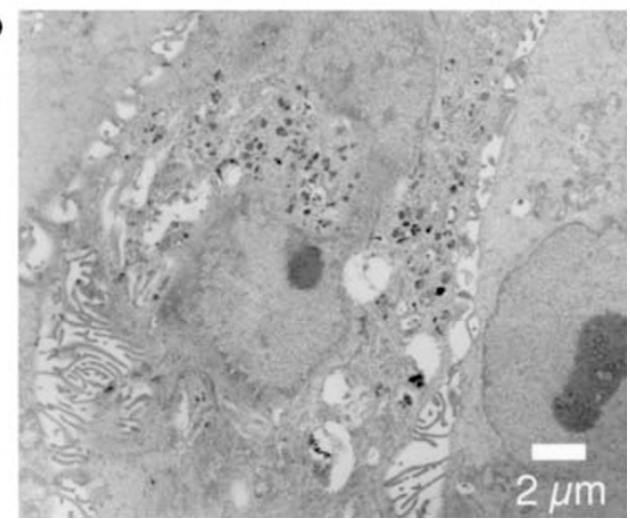

Figure 4 Electron micrographs of OSC70, untreated cells as control (a) and cells at $72 \mathrm{~h}$ after treatment with IFN- $\gamma(1000 \mathrm{IU} / \mathrm{ml})(\mathbf{b})$

lytically activated in cells undergoing apoptosis, ${ }^{25,26}$ during IFN- $\gamma$ treatment. Caspase- 3 activation was determined using two approaches, detection of active caspase- 3 fragments by Western blotting and enzymatic activity using Ac-DEVD- $p$-NA as a substrate. Active caspase- 3 fragments (p19 and p17) were observed on IFN- $\gamma$ treatment. However, the amounts of active fragments were considerably lower than those generated by treatment with the apoptosis-inducing agent, cisplatin (Figure 5a). IFN- $\gamma$-induced caspase-3 activity was estimated by comparison with that in cell lysates treated with granzyme $\mathrm{B}$, a direct activator of caspase-3 by proteolysis. ${ }^{27,28}$ Caspase- 3 was weakly, but significantly, activated by IFN- $\gamma$ (Figure 5b). The activation was specific for caspase-3, because it was inhibited by addition of an inhibitor, AcDEVD-CHO. The results suggest that IFN- $\gamma$ effectively induces the apoptotic signal to the point of partial caspase-3 activation, but not to the extent of causing typical apoptotic cell death.

\section{Protein levels of molecular chaperones in oral SCC cells during IF $\mathrm{N}-\boldsymbol{\gamma}$ treatment}

We examined the mechanism by which molecular chaperones, some of which function to modulate apoptotic events, $9,12,13$ contribute to IFN- $\gamma$-induced cell death. Protein levels of molecular chaperones in cells were determined by
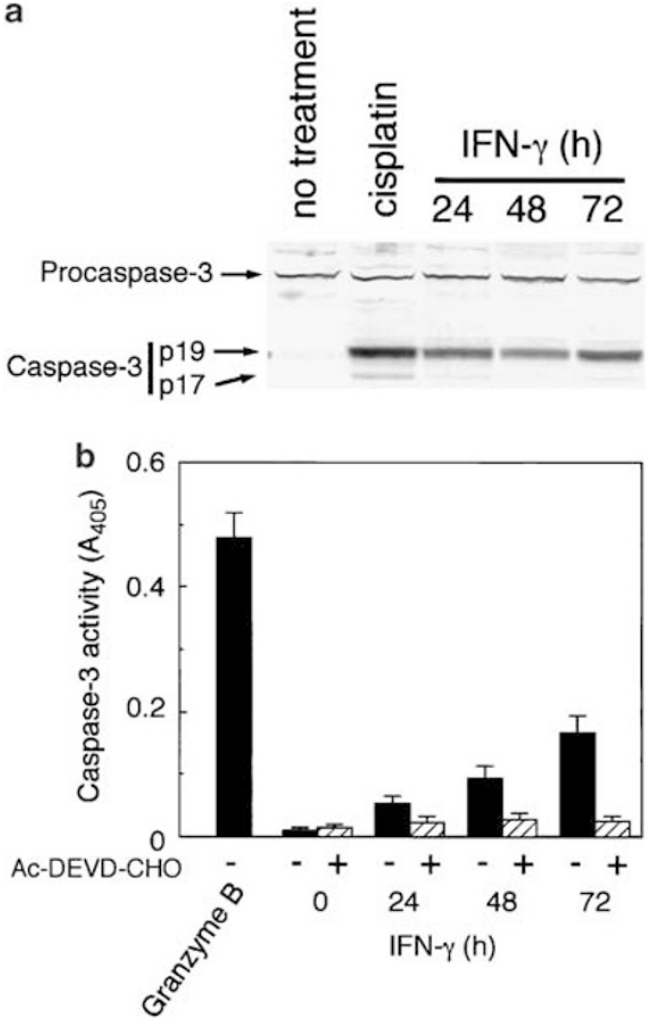

Figure 5 Caspase-3 activation in IFN- $\gamma$-treated OSC70 cells determined by cleavage of procaspase-3 (a) and enzymatic activity of caspase-3 (b). OSC70 cells were treated with $1000 \mathrm{IU} / \mathrm{ml} \mathrm{IFN}-\gamma$ for various times. (a) Cell lysate prepared from the treated cells was analyzed by Western blotting using anticaspase- 3 antibody. Procaspase- 3 ( $32 \mathrm{kDa}$ ) and active caspase- 3 fragments ( 19 and $17 \mathrm{kDa}$ ) formed by cleavage of the procaspase- 3 were detected by the antibody. For a positive control for caspase-3 activation, OSC70 cells were treated with $3 \mu \mathrm{g} / \mathrm{ml}$ of cisplatin for $18 \mathrm{~h}$. (b) Caspase-3 activity in the cell lysate was determined by using Ac-DEVD-pNA as a substrate. The experiment was performed in triplicate, and the value is expressed as mean \pm S.D. The specificity of caspase-3 activity was confirmed by inhibition in addition of caspase-3 inhibitor, Ac-DEVD-CHO. A positive control for caspase-3 activity was prepared by treating OSC70 cell lysate with granzyme $B$

Western blotting. Among the various molecular chaperones, including those from cytosol and endoplasmic reticulum, Hsp27 levels were specifically and dramatically reduced by IFN- $\gamma$. However, IFN- $\alpha$ and TNF- $\alpha$ had little effect on Hsp27 expression. Results from OSC70 cells are shown in Figure 6. On IFN- $\gamma$ treatment of OSC70, Hsp70 levels were also slightly decreased, while Hsp27 expression was more rapidly and dramatically suppressed. This specific decrease in Hsp27 was observed in most SCC cells tested, but not in HeLa cells (Figure 7). Among the oral SCC cells, OSC70 and OSC19, which are more sensitive to the effects of IFN- $\gamma$ (Figure 1a), revealed a more significant decrease in Hsp27 levels.

\section{Role of Hsp27 in IFN- $\gamma$-induced cell death}

To clarify the role of Hsp27 in IFN- $\gamma$-induced cell death, we established recombinant clones stably overexpressing human Hsp27. Representative clones were designated OSC70- 


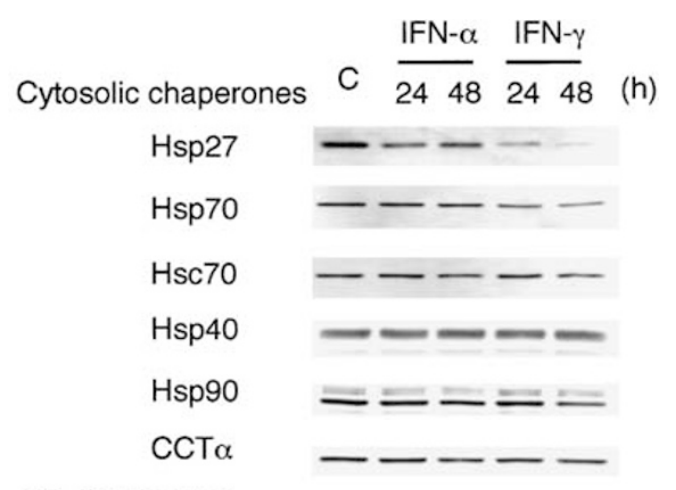

ER chaperones

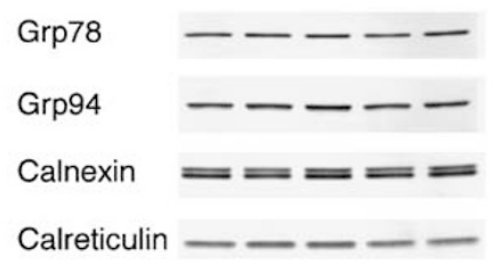

Mitochondrial chaperone

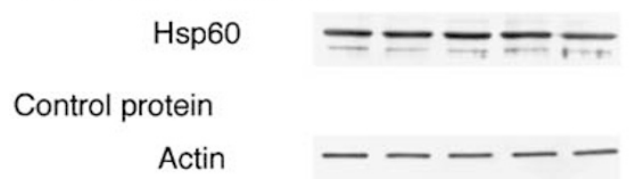

Figure 6 Protein levels of molecular chaperones in OSC70 cells during treatment with IFN- $\alpha$ or IFN- $\gamma$. OSC70 cells were treated with IFN- $\alpha(1000 \mathrm{IU} / \mathrm{ml})$ or IFN- $\gamma(1000 \mathrm{IU} / \mathrm{ml})$. The resulting cells were lysed, and the soluble protein ( $5 \mu \mathrm{g}$ protein per lane) was separated by SDS-PAGE and quantified by Western blotting using the specific antibodies. Actin was used as control for protein loading

27.1, OSC70-27.2 and OSC70-27.3 (derived from OSC70), and OSC19-27.1, OSC19-27.2 and OSC19-27.3 (derived from OSC19). The Hsp27 expression of the parent cells and their clones was determined by Western blotting as shown in Figure $8 \mathrm{~b}$ (OSC70 and its clones) and Figure $8 \mathrm{e}$ (OSC19 and its clones). The clones expressed 5- to 12-fold more Hsp27 than parent OSC70 cells and 8- to 15-fold more Hsp27 than parent OSC19 cells. The phosphorylated form of Hsp27 also increased in a proportional manner. This observed increase in Hsp27 appeared to be because of products derived from the exogenous Hsp27 gene and not induction by stress stimulation caused by exogenous gene expression, since levels of $\mathrm{Hsp} 70$ in the clones were not significantly different from those in the parent cells. The Hsp27-overexpressing clones displayed resistance to cisplatin-induced apoptosis (data not shown), consistent with earlier reports. ${ }^{29-31}$ Moreover, these recombinant constructs were significantly more resistant to IFN- $\gamma$-induced cell death than control cells (Figure 8a and d). The overexpressed exogenous Hsp27 in the transfectants also decreased during IFN- $\gamma$ treatment, but the protein levels in the treated transfectants were still more than those in untreated control cells (Figure 8c and f).

We additionally established recombinant OSC70 clones stably expressing a dominant-negative mutant of Hsp27, Hsp27-Gly. In the Hsp27-Gly mutant, three serine residues

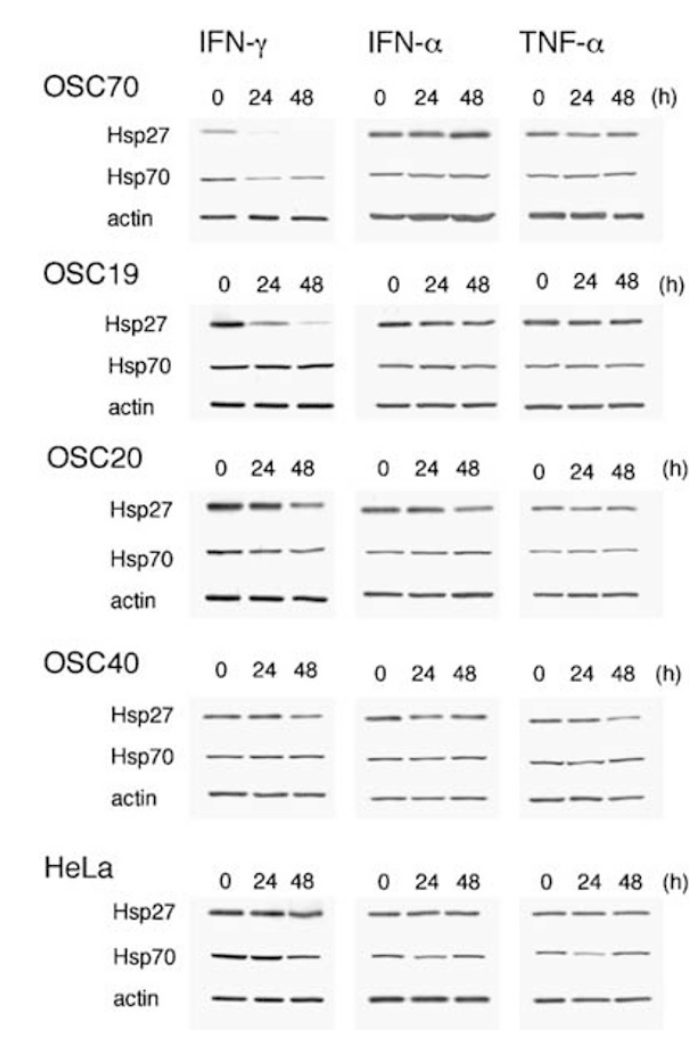

Figure 7 Protein levels of Hsp27 and Hsp70 in oral SCC cells and HeLa cell during IFN- $\gamma$ treatment. The cells were treated with IFN- $\alpha(1000 \mathrm{IU} / \mathrm{ml})$ or IFN- $\gamma$ $(1000 \mathrm{IU} / \mathrm{ml})$ for 24 or $48 \mathrm{~h}$. The resulting cells were lysed, and the soluble protein ( $5 \mu \mathrm{g}$ protein per lane) was applied to SDS-PAGE and the Western blotting using the specific antibodies. Actin was used as control for protein loading

(Ser-15, -78 and -82) that function as phosphorylation sites. $^{23,32}$ are substituted with glycine residues. ${ }^{21-23,33}$ Phosphorylation of $\mathrm{Hsp} 27$ is induced by various extracellular stimuli and contributes to the structural organization of the protein. ${ }^{32}$ The chaperone activity of Hsp27 is regulated by its incorporation into a large oligomeric complex. Phosphorylation of the three Hsp27 serine residues negatively regulates the formation of the large oligomer. ${ }^{32}$ These Hsp27 mutants containing alternative residues in place of serine became phosphorylated and exhibited a different structural organization pattern. For example, mutants containing substituted glycine or aspartic acid residues appeared to be monomeric or small oligomeric structures with corresponding molecular weights of less than $200 \mathrm{kDa}$, as estimated by gel filtration chromatography. In contrast, another Hsp27 mutant containing substituted alanine residues formed a much larger complex of more than $400 \mathrm{kDa}{ }^{33}$ The amounts of other HSPs, such as Hsp70, and the phosphorylated form of Hsp27 did not alter in the recombinant clones compared to parental cells (Figure 9a). This suggested that exogenous Hsp27-Gly should specifically overexpress in these clones, however, endogenous Hsp27 levels should not be influenced by expression of the exogenous gene. Furthermore, gel filtration on Superose 6 revealed that the larger oligomer containing endogenous Hsp27 and exogenous Hsp27-Gly was not observed in OSC70 clones expressing Hsp27-Gly (Figure 9b). Therefore, 


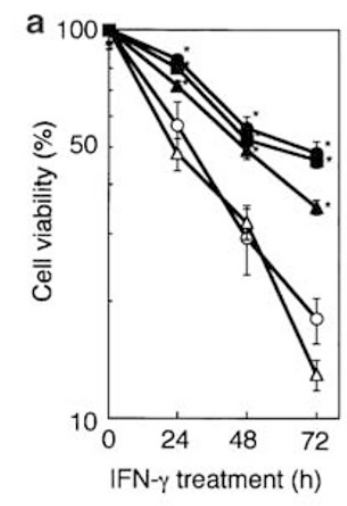

b

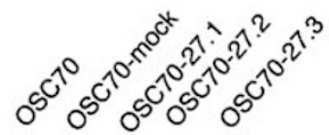

Hsp27

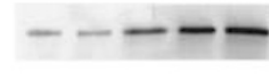

p-Hsp27 (S15)

Hsp70

C

$$
\text { IFN- } \gamma \text { treatment }(h)
$$$$
0 \quad 24 \quad 48
$$

\section{Osc70}

OSC70-27.3

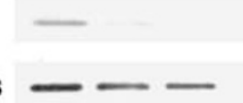

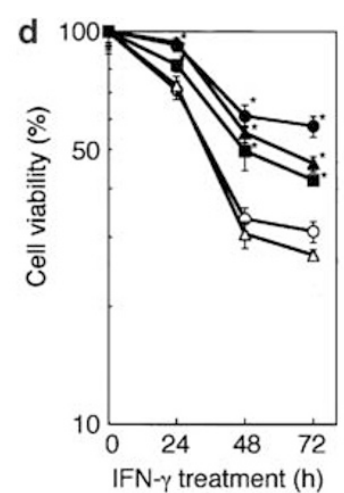

e
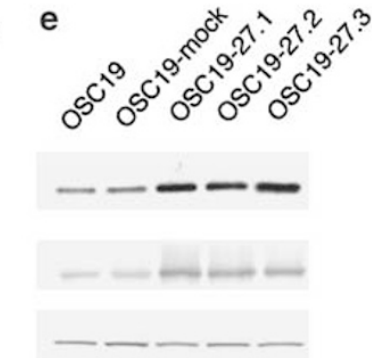

f

IFN- $\gamma$ treatment (h)

$0 \quad 24 \quad 48$

OSC19
OSC19-27.1 - -

Figure 8 Suppression of IFN- $\gamma$ induced cell death by overexpression of $\mathrm{Hsp} 27$ in OSC70 (a, b and $\mathbf{c})$ and OSC19 (d, e and $\mathbf{f})$. The expression plasmid encoding human Hsp27 was transfected to OSC70 and OSC19. Clones stably expressing Hsp27 were then selected. The results of representative clones are shown. OSC70-mock and OSC19-mock indicate transformants of control plasmid. (a and d) Cell viability during IFN- $\gamma$ treatment. Used symbols: OSC70 (O), OSC70-

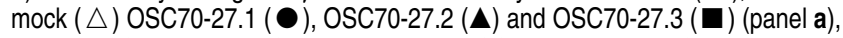
and are OSC19 $(\mathrm{O})$, OSC19-mock $(\triangle)$ OSC19-27.1 ( $)$, OSC19-27.2 $(\boldsymbol{\Delta})$ and OSC19-27.3 (घ) (panel d). The cells were treated with $1000 \mathrm{IU} / \mathrm{ml} \mathrm{IFN}-\gamma$ for various times. Cell viability of the treated cells were determined by the formazanformation assay. The experiments were carried out in quadruplicate, and the value was expressed as mean \pm S.D. * Indicates significant difference $(P<0.01)$ from OSC70-mock. (b and e) Protein expression of Hsp27, phosphorylated Hsp27 (Ser15) and Hsp70 in the clones was determined by Western blotting. The Hsp70 expression was used as a control for this experiment. (c and f) Changes of Hsp27 protein levels in the parent cells and the Hsp27-overexpressing transfectants during IFN- $\gamma$ treatment were determined by Western blotting

the Hsp27-Gly mutant in OSC70 cells should have a dominant-negative effect on the formation of large oligomers which have chaperone activity. The chromatographic behaviors of Hsp27 in the parent cells and the Hsp27-Gly transfectants were not significantly changed during IFN- $\gamma$ treatment, except that total amounts of Hsp27 were decreased (data not shown).

Hsp27-Gly-expressing OSC70 clones were hypersensitive to IFN- $\gamma$ (Figure 10a) and cisplatin (Figure 10b) compared to control cells, OSC70 and mock-transfected OSC70. In addition, DNA fragmentation data show that cells expressing Hsp27-Gly exhibit typical apoptotic phenotypes (Figure 10c). a

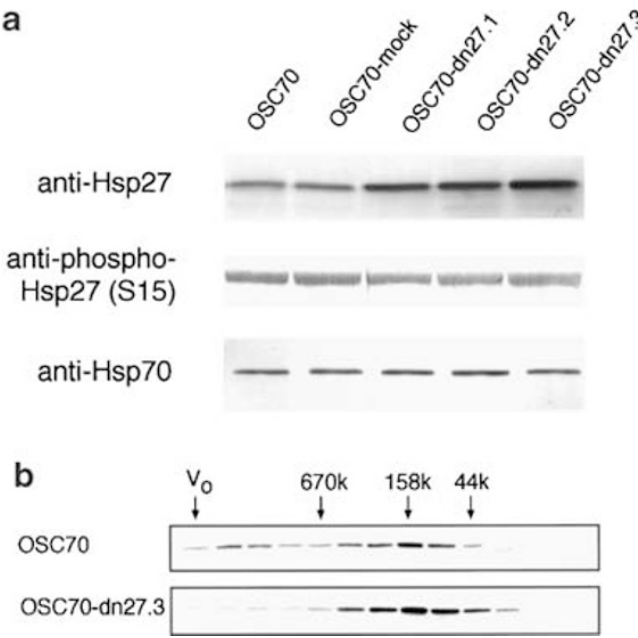

Figure 9 Establishment of OSC70 clones stably expressing a dominantnegative mutant Hsp27-Gly. Protein expression of Hsp27 (and Hsp27-Gly), phosphorylated Hsp27 and Hsp70 determined by Western blotting (a), and oligomeric status of Hsp27 and Hsp27-Gly in an OSC70 clone expressing Hsp27Gly (OSC70-dn27.3) determined by gel filtration chromatography (b). The expression plasmid encoding mutant Hsp27 gene, in which phosphorylation sites Ser-15, -78 and -82 residues, were converted to Gly, was transfected to OSC70, and clones stably expressing the mutant $\mathrm{Hsp} 27$-Gly were selected. Results for representative clones, OSC70-dn27.1, OSC70-dn27.2 and OSC70-dn27.3, and a transformant of control plasmid (OSC70-mock) are shown. (a) Protein levels of Hsp27-Gly and endogenous Hsp27 were detected by Western blotting using the anti-Hsp27 antibody. Levels of phosphorylated Hsp27 and Hsp70 were determined. (b) Cell lysates from OSC70 and OSC70-dn27.3 were applied to a Superose 6 column. Elution profile of anti-Hsp27 antibody-reactive materials, wild-type Hsp27 and Hsp27-Gly, were detected by Western blotting using antiHsp27 antibody. Elution positions of molecular weight standards (bovine thyroglobulin $(670000), \gamma$-globulin $(158000)$ and chicken ovalbumin $(44000))$ are shown at the top of the figure

Activation of caspase-3 in these cells was also greater than that in parent cells, as ascertained by the formation of active caspase-3 fragments (p19 and p17) (Figure 10d) and caspase-3 enzymatic activity (Figure 10e). These results indicate that the structural organization of Hsp27, specifically the ability to form large oligomers, involved in its inhibitory activity cell death. According to lines of evidence, Hsp27 in oral SCC cells plays a critical role in the negative regulation of apoptotic cell death. IFN- $\gamma$ stimulates the cell death signal via its inhibitory effect of Hsp27, although not sufficiently to cause complete apoptotic cell death. In oral SCC cells, IFN- $\gamma$ downregulates protein levels of $\mathrm{Hsp} 27$, and therefore possibly promotes the proapoptotic state by partially activating caspase-3 (Figure 5). Our findings suggest that typical apoptotic cell death occurs by the suppression of residual Hsp27 activity following IFN- $\gamma$ treatment in the dominantnegative mutant, Hsp27-Gly.

\section{Synergistic activity of cisplatin and IFN- $\gamma$ on apoptotic cell death in oral SCC cells}

Our results indicate that IFN- $\gamma$ promotes the proapoptotic state in oral SCC cells. To confirm this, we examined the synergistic effect of IFN- $\gamma$ and cisplatin treatment on apoptotic cell death. The degree of apoptosis was estimated from DNA 

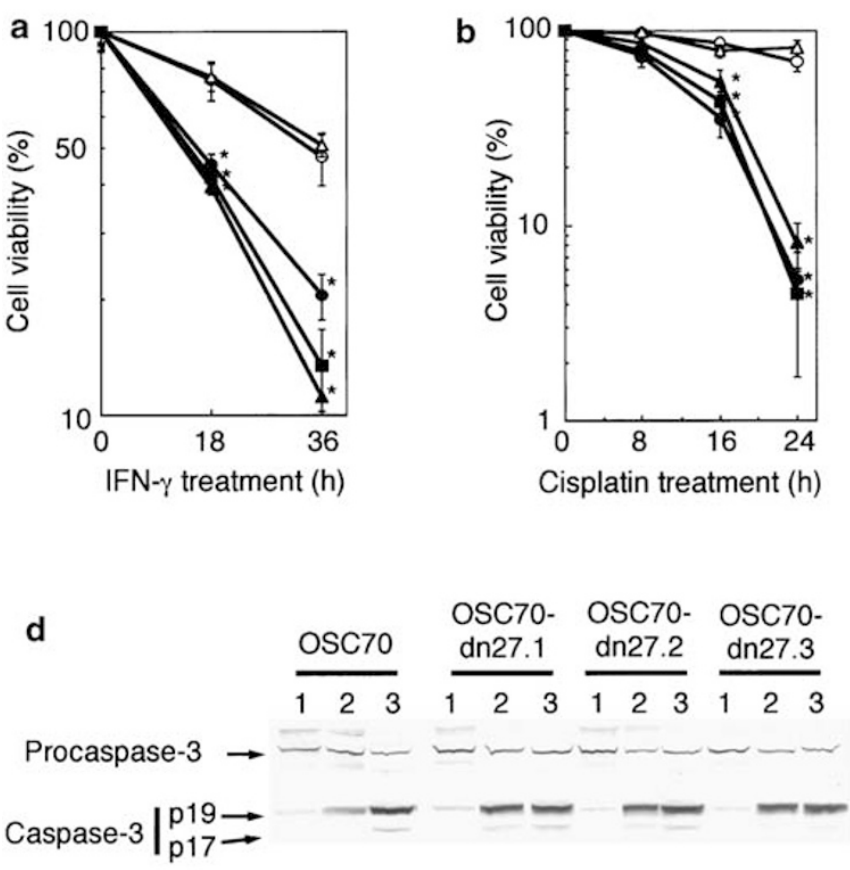

b

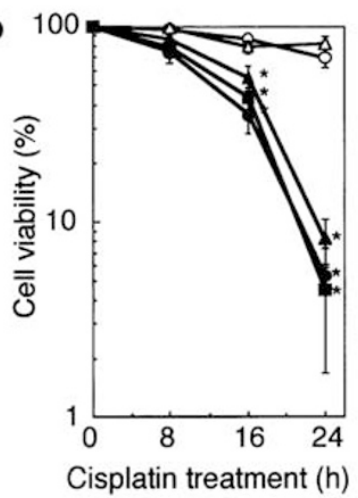

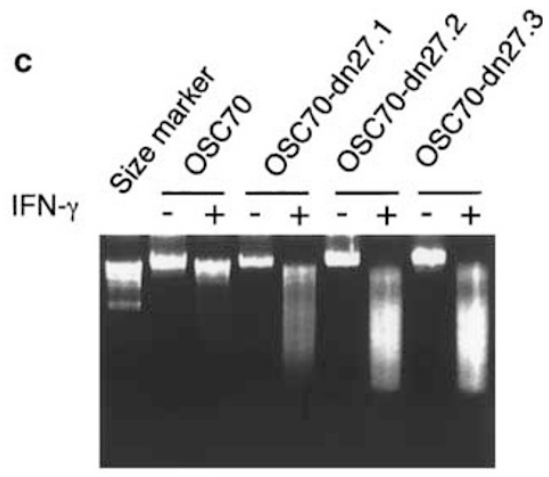

e

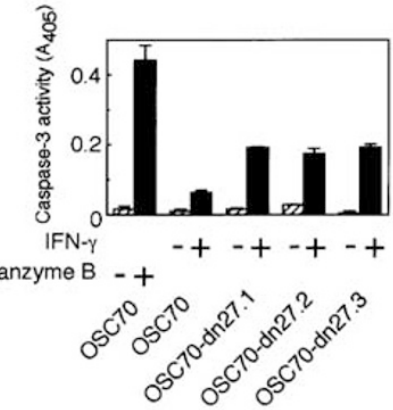

Figure 10 OSC70 clones stably expressing a dominant-negative mutant Hsp27-Gly are hypersensitive to IFN- $\gamma$. Results for representative clones are shown. The

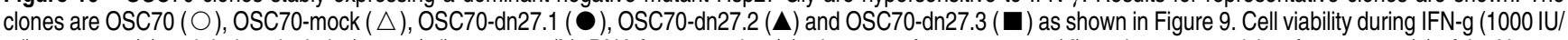
$\mathrm{ml})$ treatment $(\mathbf{a})$ and during cisplatin $(0.3 \mu \mathrm{g} / \mathrm{ml})$ treatment $(\mathbf{b})$. DNA fragmentation $(\mathbf{c})$, cleavage of procaspase-3 (d), and enzyme activity of caspase-3 (e) of the Hsp27Gly-expressing clones were determined during treatment with $1000 \mathrm{IU} / \mathrm{ml} \mathrm{IFN-} \gamma$. (a) Cell viability was determined by the formazan-formation assay. The experiments were carried out in quadruplicate, and the value was expressed as mean \pm S.D. * Indicates significant difference $(P<0.01)$ from OSC70-mock. (c) DNA fragmentation was determined $36 \mathrm{~h}$ after the addition of IFN- $\gamma$. The extracted DNA was applied to $1.5 \%$ agarose gel electrophoresis and stained by ethidium bromide. (d and $\mathbf{e}$ ) Cleavage of procaspase-3 and caspase- 3 activity were determined $18 \mathrm{~h}$ after the addition of IFN- $\gamma$ or cisplatin $(3 \mu \mathrm{g} / \mathrm{ml})$ determined by Western blotting and colorimetric assay using Ac-DEVD-pNA as a substrate, respectively, as shown in Figure 5. In panel d, lanes 1, 2 and 3 indicate untreated control, IFN- $\gamma$ treatment and cisplatin treatment, respectively. In panel e, a positive control for caspase-3 activity was cell lysate treated with granzyme $B$

fragmentation, which was determined by BrdU-containing DNA fragments release from BrdU-labeled cells. As shown previously ${ }^{7}$ and in Figure 3, IFN- $\gamma$ treatment did not result in significant DNA ladder formation. However, pretreatment with IFN- $\gamma$ dramatically enhanced cisplatin-induced DNA ladder formation. This synergism was observed at cisplatin concentrations of $0.3-1 \mu \mathrm{g} / \mathrm{ml}$ in OSC70, and at a concentration of $3 \mu \mathrm{g} / \mathrm{ml}$ in OSC19 cells (Figure 11), but not in HeLa cells (data not shown).

\section{Discussion}

Numerous oral SCC cell lines are highly sensitive to IFN- $\gamma$ induced cell death. SCC cells treated with IFN- $\gamma$ underwent severe growth arrest, followed by death. This type of cell death was not observed in the other cell lines tested, including HeLa (Figure 1), amnion cell line FL and monocytic cell line U937 (data not shown). IFN- $\gamma$-treated cells did not display typical apoptotic phenotypes. However, IFN- $\gamma$-treatment augmented apoptotic cell death caused by certain inducers, including Verotoxin ${ }^{7}$ and cisplatin (Figure 11). The apoptotic pathway executioner factor, caspase- $3,{ }^{25,26}$ is significantly activated by IFN- $\gamma$ in oral SCC cells, although not to a major degree, since IFN- $\gamma$-induced caspase- 3 activity is much lower than that in positive controls treated with granzyme B (Figure 5). These results collectively suggest that the apoptotic signal is transduced by IFN- $\gamma$. However, we postulate that some factor(s) inhibit this signal transduction, consequently prevent typical apoptosis.

Certain HSPs, such as Hsp70 and Hsp27, act as suppressors of apoptotic cell death (reviewed in Creagh et al., ${ }^{9}$ Jolly and Morimoto ${ }^{10}$, Samali and Orrenius, ${ }^{12}$ Xanthoudakis and Nicholson ${ }^{13}$ and Beere and Green $\left.{ }^{26}\right)$. Recent reports show that abrogation of $\mathrm{Hsp} 70$ expression by using antisense oligonucleotides triggers apoptotic cell death in human $\mathrm{SCC}^{34}$ and breast cancer cells. ${ }^{35}$ In this study, we demonstrated that the protein levels of Hsp27 in SCC cells are specifically reduced by IFN- $\gamma$ treatment. However, expression of other molecular chaperones was not affected. IFN- $\gamma$ induced decrease in Hsp27 and cell death was not observed in any other cell lines tested, including HeLa. We therefore propose that Hsp27 plays a crucial role in the inhibition of apoptotic cell death in SCC cells. Moreover, clones stably overexpressing Hsp27 were significantly resistant to the effects of IFN- $\gamma$ (Figure 8). We additionally examined the effects of mutant Hsp27-Gly, in which three serine residues are substituted for glycine, on IFN- $\gamma$-induced cell death. The Hsp27-Gly mutant acts as a dominant-negative form of its 


\section{OSC70}
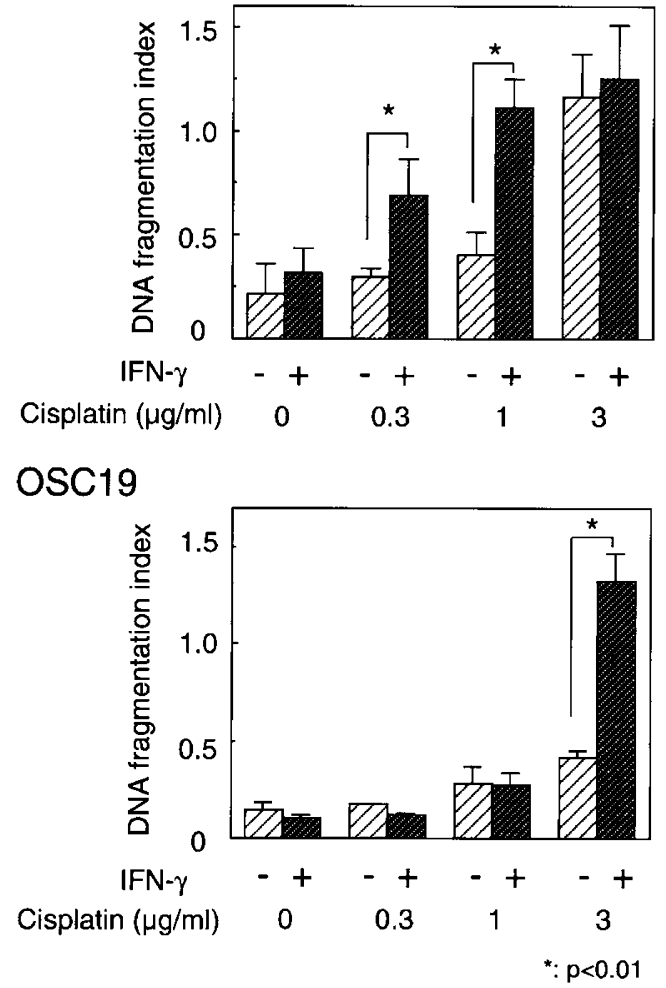

Figure 11 Augmentation of cisplatin-induced apoptosis by IFN- $\gamma$ pretreatment in OSC70 and OSC19. The BrdU-labeled cells were either pretreated with $1000 \mathrm{IU} / \mathrm{ml} \mathrm{IFN}-\gamma$ for $4 \mathrm{~h}$ or left untreated. After removal of IFN- $\gamma$, various concentrations of cisplatin were added and cells were incubated for an additional $24 \mathrm{~h}$. The resulting supernatant containing the apoptotic cells was collected, and DNA fragmentation was determined by quantifying soluble BrdU-containing DNA fragment using ELISA. The experiments were performed in quadruplicate. The values are expressed as mean \pm S.D.

wild-type counterpart. ${ }^{21,22,33}$ Hsp27 is regulated at both transcriptional and post-transcriptional levels. In the latter, Hsp27 is phosphorylated in response to various cytokines and growth/differentiation factors and during periods of cellular stress, such as heat shock and oxidative stress ${ }^{23}$ by MAPKAP kinase $2 / 3 .^{36,37}$ Phosphorylation of $\mathrm{Hsp} 27$ negatively regulates the protein structural organization (i.e. oligomerization), its function as a molecular chaperone and, consequently, its protective activity against oxidative stress and TNF- $\alpha .{ }^{32}$ Bruey et $a^{\beta 8}$ showed that amino acids $51-88$, which include the latter two of the three phosphorylatable serine residues, of Hsp27 comprise one of the regions necessary for cytochrome $c$ binding and consequent inhibition of caspase activation. However, the Hsp27-Gly mutant cannot be phosphorylated, is not incorporated into large oligomeric complexes and probably disrupts the large oligomer containing endogenous Hsp27 (Figure 9b). Thus, the Hsp27-Gly is structurally similar to phosphorylated Hsp27, as similar as a mutant Hsp27S15D,S78D,S82D in which substituted aspartic acid residues mimic phosphoserine residues and act in a dominant-negative manner against the functional Hsp27 complex. ${ }^{32}$ Hsp27-Glyexpressing cells lack both molecular chaperone activity of
Hsp27 and protection against oxidative stress. ${ }^{22,33}$ In our experiments, recombinant SCC clones expressing Hsp27-Gly were highly sensitive to IFN- $\gamma$ and exhibited the typical apoptotic phenotypes. Furthermore, IFN- $\gamma$-induced caspase3 activation in cells expressing Hsp27-Gly was much higher than that in the parent cells (Figure 10d,e). These data suggest that the suppression of caspase- 3 activation fails to occur in the presence of the dominant-negative mutant of Hsp27. In other words, the structural organization (i.e. larger complex formation) of Hsp27 controlled by its phosphorylation is essential for the suppression of oral SCC cell apoptosis. IFN- $\gamma$ appears to promote the transition of oral SCC cells to a proapoptotic state and decrease in Hsp27 probably contributes to this response. However, IFN- $\gamma$ alone does not induce typical apoptosis. Residual Hsp27 following IFN- $\gamma$ treatment may inhibit full activation of caspase-3 and typical complete apoptosis. In addition to multiple functions in negative regulation of apoptosis, Hsp27 plays other important roles in the cell, such as organization of the actin cytoskeleton. ${ }^{39,40}$ In the mitochondrial (receptor-unmediated) apoptotic pathway, three Hsp27-regulated mechanisms have been reported. These include the inhibition of reactive oxygen species formation, increase in cellular levels of glutathione, ${ }^{41,42}$ interactions with cytochrome $c$ released from mitochondria $^{38,43}$ and inhibition of caspase- 3 activation via direct interactions. ${ }^{44}$ In the death receptor-mediated pathway, Hsp27 inhibits Fas-induced Daxx and Ask1-dependent apoptosis. ${ }^{45}$ However, the specific role of $\mathrm{Hsp} 27$ in oral SCC cells is currently unclear.

To our knowledge, transcription of Hsp27 is controlled by heat shock elements and estrogen-responsible elements, as revealed by studies on the murine gene. ${ }^{46}$ However, the molecular mechanism responsible for the IFN- $\gamma$-dependent decrease in Hsp27 is yet to be revealed. However, in RNA levels and transcriptional activity of the Hsp27 decreased during IFN- $\gamma$ treatment. It seemed to be non-specific, because other control mRNAs, such as actin, and SV40 promoter activity were also decreased (data not shown). This should be due to that IFN- $\gamma$ strongly arrests the growth of oral SCC cells. Our results suggest that the decrease in levels of Hsp27 protein induced by IFN- $\gamma$ is specific to oral SCC cells. In other cell lines, such as the human monocytic U937, Hsp27 expression is upregulated on IFN- $\gamma$ treatment (data not shown). This cell type-specific regulation of Hsp27 expression is currently under investigation.

Overexpression of Hsp27 correlates with increased resistance to certain anticancer drugs. ${ }^{29-31}$ Our findings (Figure 8) are in agreement with these earlier reports. Several studies, although not all, indicate that Hsp27 is preferentially expressed in certain types of malignant tumor [reviewed in Jättelä ${ }^{47,48}$ and Arrigo ${ }^{49}$ ]. Our experiments well explain that high levels of Hsp27 in tumor cells are associated with poor prognosis and, consequently, significantly reduced survival of cancer patients. In contrast, oral SCC cells that express lower levels of Hsp27 are more sensitive to the apoptotic stimuli. In oral SCC cells, IFN- $\gamma$ downregulates Hsp27 expression and therefore promotes cells to a proapoptotic state and/or aborted apoptosis. According to Leist and Jäättelä, ${ }^{14}$ aborted apoptosis represents a subgroup of necrosis-like programmed cell death. A typical apoptosis program is initiated, 
blocked at the level of caspase activation and finally terminated by alternative routes. IFN- $\gamma$ alone does not induce apoptosis, probably because it does not completely terminate Hsp27 expression and function. This study at the molecular level supports the potential therapeutic benefits of a treatment strategy combining IFN- $\gamma$ with other anticancer drugs, such as cisplatin. Additionally, Hsp27 may be a useful maker of sensitivity to anticancer drugs in oral SCC.

\section{Materials and Methods}

\section{Cell lines and culture}

Human oral SCC lines (OSC19, OSC20, OSC30, OSC40 and OSC70) ${ }^{7}$ were established from metastatic oral squamous carcinomas as described previously. ${ }^{15-17}$ OSC40 was derived from the oral floor, while other cell lines were obtained from the tongue. OSC19 and OSC30 were derived from moderately differentiated SCC, and OSC20, OSC40 and OSC70 were obtained from well-differentiated SCC. HeLa was obtained from American-type culture collection (Rockville, MD, USA). All cells were cultured in RPMI-1640 supplemented with $10 \%$ heat-inactivated fetal bovine serum in $5 \% \mathrm{CO}_{2}$ at $37^{\circ} \mathrm{C}$.

\section{Cytokine treatment and determination of cell viability}

Cells were treated with $1000 \mathrm{IU} / \mathrm{ml}$ IFN- $\gamma$ (Genzyme, Cambridge, MA,

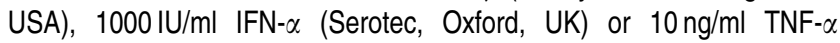
(Genzyme). The viability of treated cells was determined with the formazan-formation assay using the cell counting kit-8 (DOJINDO Laboratories, Kumamoto, Japan).

\section{Electron microscopy}

OSC70 cells treated with IFN- $\gamma(1000 \mathrm{IU} / \mathrm{ml})$ for $72 \mathrm{~h}$ were processed for electron microscopy, along with untreated OSC70 as a control. A total of $10^{6}$ cells for each sample were fixed with $2 \%$ paraformaldehyde and $2.5 \%$ glutaraldehyde in $0.1 \mathrm{M}$ phosphate buffer, $\mathrm{pH} 7.4$, for $30 \mathrm{~min}$ at $4{ }^{\circ} \mathrm{C}$ and postfixed with $1 \% \mathrm{OsO}_{4}$ in the same buffer for $1 \mathrm{~h}$ at $4{ }^{\circ} \mathrm{C}$. After dehydration, embedding in Epon, ultrathin-sectioning and staining with uranyl acetate and lead citrate, samples were examined in a JEOL 1200EX.

\section{Western blotting}

Mouse monoclonal antibodies to Hsp27 (clone G3.1), Hsp60 (LK-1), Hsp70 (C92F3A-5), Hsp90 (AC88), calnexin (AF18), calreticulin (FMC 75) and KDEL (10C3; for detecting Grp78 and Grp94), rat monoclonal antibodies to $\mathrm{Hsc70}$ (1B5) and CCT $\alpha$ (84a) and rabbit polyclonal antibody to Hsp40 were purchased from StressGen (Victoria, BC, Canada). Sheep polyclonal antibody to phospho-Hsp27 (Ser15) was purchased from Upstate Biotechnology (Lake Placid, NY, USA). Rabbit polyclonal antibody to caspase-3 was purchased from Pharmingen (San Diego, CA, USA). Mouse monoclonal antibody to actin (C4) was from Chemicon (Temecula, CA, USA).

Cells were lysed with a solution containing 1\% Nonidet P-40, $120 \mathrm{mM}$ $\mathrm{NaCl}, 1 \mathrm{mM}$ dithiothreitol, $10 \%$ glycerol, $5 \mathrm{mM}$ EDTA, $1 \mathrm{mM}$ phenylmethylsulfonyl fluoride, $1 \mathrm{mM} \mathrm{Na}_{3} \mathrm{VO}_{4}, 1 \mathrm{mM} \mathrm{NaF}$ and $20 \mathrm{mM} \mathrm{HEPES}-\mathrm{NaOH}$, $\mathrm{pH}$ 7.5 , and lysates were centrifuged at $5000 \times g$ for $10 \mathrm{~min}$ at $4^{\circ} \mathrm{C}$. Supernatants were collected, and protein concentrations were determined by the method of Bradford ${ }^{18}$ using bovine serum albumin as a standard. Sodium dodecylsulfate-polyacrylamide gel electrophoresis (SDS-PAGE) and Western blotting were performed as described previously. ${ }^{19,20}$ Alkaline phosphatase-conjugated anti-immunoglobulin $(\mathrm{lg})$ antibodies and tetrazolium bromochloroindolyl phosphate/nitro blue tetrazolium were used as secondary antibody and developing substrate, respectively, for the Western blotting. Alkaline phosphatase-conjugated anti-sheep Ig antibody was purchased from Chemicon.

\section{Plasmids and establishment of stable transformants}

Expression plasmids harboring human Hsp27 cDNA and the Hsp27-Gly gene (pKSm157882) were produced as previously described. ${ }^{21,22}$ The pKSm157882 plasmid was generously provided by Dr. LA Weber. ${ }^{23}$ This construct contains the mutant Hsp27 gene in which the codons for Ser-15, Ser-78 and Ser-82 are converted to the glycine-coding sequence by sitedirected mutagenesis. Expression vectors were constructed using the cytomegalovirus promoter (pRc/CMV, Invitrogen, San Diego, CA, USA).

Transfection of the expression plasmid into target cells was performed using SuperFect Reagent (QIAGEN, Hilden, Germany) according to the manufacturer's instructions. Stably expressed clones were selected and maintained in culture medium containing geneticin at concentrations of $800 \mu \mathrm{g} / \mathrm{ml}$ (for OSC70) or $200 \mu \mathrm{g} / \mathrm{ml}$ (for OSC19). Transformants of pRc/ CMV were also established and used as a control experiment. Wild-type and mutant Hsp27, Hsp27-Gly, protein expression was confirmed by Western blotting using the mouse monoclonal anti-Hsp27 antibody (clone G3.1) as above.

\section{Gel filtration}

Cell extracts were prepared as described in the Western blotting section, and applied to a Superose six column $(1 \times 30 \mathrm{~cm}$ ) (Amersham Pharmacia Biotech, Uppsala, Sweden) equilibrated with phosphate-buffered saline. Chromatography was performed at $1 \mathrm{ml} / \mathrm{min}$ with an FPLC system (Amersham Pharmacia Biotech). Fractions (1 $\mathrm{ml}$ each) were collected, and aliquots were analyzed by Western blotting as described.

\section{Induction and determination of apoptotic cell death}

Cisplatin [cis-platinum(II)diamine dichloride] (Sigma-Aldrich, St. Louis, MS, USA) and Verotoxin (Shiga toxin)-2 (Nacalai Tesque, Kyoto, Japan) were employed apoptosis inducers.

To determine the extent of apoptosis, DNA fragmentation was quantified using the Cellular DNA Fragmentation ELISA kit (Roche Diagnostic, Mannheim, Germany). This assay system is based on the determination of solubilized 5-bromodeoxyuridine (BrdU)-containing DNA fragments from BrdU-labeled cells undergoing apoptosis. DNA fragmentation in apoptotic cells was also determined by agarose electrophoresis using a protocol described previously. ${ }^{7,24}$

\section{Enzymatic activity of caspase-3}

Caspase-3 activity in cell lysate was determined with a colorimetric assay kit (MBL, Nagoya, Japan). The principle of this method is the monitoring of $p$-nitroaniline $(p N A)$ release from a caspase-3 substrate, Ac-DEVD-pNA. The background control was prepared by adding the caspase- 3 inhibitor, Ac-DEVD-CHO (Peptide Institute Inc., Osaka, Japan), to cell lysate at a concentration of $10 \mu \mathrm{M}$. As a positive control for caspase-3 activation, cell 
lysate were treated with $5 \mathrm{ng} / \mathrm{ml}$ granzyme B (Calbiochem, San Diego, CA, USA) at $37^{\circ} \mathrm{C}$ for $1 \mathrm{~h}$. Enzymatic activity was calculated at an absorbance of $405 \mathrm{~nm}$

\section{Effect of IFN- $\gamma$ pretreatment on apoptotic cell death}

Cells cultured in 96-well plates were labeled with $10 \mu \mathrm{M}$ BrdU for $2 \mathrm{~h}$. After washing, $1000 \mathrm{IU} / \mathrm{ml} \mathrm{IFN-} \gamma$ was added and cells were incubated at $37^{\circ} \mathrm{C}$ for $4 \mathrm{~h}$. Following the removal of IFN- $\gamma$, various concentrations of cisplatin (dissolved in dimethylsulfoxide; $10 \mathrm{mg} / \mathrm{ml}$ stock solution) were added and cells were incubated for $24 \mathrm{~h}$. The resulting cell supernatant was collected and applied to the Cellular DNA Fragmentation ELISA kit. Significant DNA fragmentation was not observed in residual adhering cells. The extent of apoptosis (i.e. the apoptosis index) was expressed as absorbance at $450 \mathrm{~nm}$.

\section{Statistical analysis}

Results are expressed as mean \pm S.D. Significant difference between two mean values was determined by unpaired $t$-test.

\section{References}

1. Rosenberg B. (1985) Fundamental studies with cisplatin. Cancer 55: 23032306

2. Nehme A, Julia AM, Jozan S, Chevreau C, Bugat R and Canal P. (1994) Modulation of cisplatin cytotoxicity by human recombinant interferon- $\gamma$ in human ovarian cancer cell lines. Eur. J. Cancer 4: 520-525

3. Lee SB and Esteban M (1994) The interferon-induced double-stranded RNAactivated protein kinase induces apoptosis. Virology 199: 491-496

4. Diaz-Guerra M, Rivas C and Esteban M (1997) Activation of the IFN-inducible enzyme RNase L causes apoptosis of animal cells. Virology 236: 354-363

5. Yeung MC, Liu J and Lau AS (1996) An essential role for the interferoninducible, double-stranded RNA-activated protein kinase PKR in the tumor necrosis factor-induced apoptosis in U937 cells. Proc. Natl. Acad. Sci. USA 93: $12451-12455$

6. Zhou A, Paranjape J, Brown TL, Nie H, Naik S, Dong B, Chang A, Trapp B, Fairchild R, Colmenares $C$ and Silverman, $\mathrm{RH}$ (1997) Interferon action and apoptosis are defective in mice devoid of $2^{\prime}, 5^{\prime}$-oligoadenylate-dependent RNase L. EMBO J. 16: 6355-6363

7. Yonekura N, Yokosawa N, Hariya Y, Dehari H, Kohama G and Fujii N (2000) Interferon-alpha and interferon-gamma augment apoptosis in oral carcinoma cells treated with Shiga toxin 2 (Stx2). Tumor Res. 35: 25-33

8. Gething M-J, ed. (1997) Guidebook to Molecular Chaperones and ProteinFolding Catalysts. Oxford: Oxford University Press

9. Creagh EM, Sheehan D and Cotter TG (2000) Heat shock proteins-modulators of apoptosis in tumor cells. Leukemia 14: 1161-1173

10. Jolly $\mathrm{C}$ and Morimoto $\mathrm{RI}(2000)$ Role of the heat shock response and molecular chaperones in oncogenesis and cell death. J. Natl. Cancer Inst. 92: 1564-1572

11. Sõti $C$ and Csermely $P$ (1998) Molecular chaperones in the etiology and therapy of cancer. Pathol. Oncol. Res. 4: 316-321

12. Samali A and Orrenius $S$ (1998) Heat shock proteins: regulators of stress response and apoptosis. Cell Stress Chaperones 3: 228-236

13. Xanthoudakis $S$ and Nicholson DW (2000) Heat-shock proteins as death determinants. Nat. Cell Biol. 2: E163-E165

14. Leist $M$ and Jäättelä $M(2001)$ Four deaths and a funeral: from caspases to alternative mechanisms. Nat. Rev. Mol. Cell Biol. 2: 589-598

15. Yokoi T, Yamaguchi A, Odajima T and Furukawa K (1988) Establishment and characterization of a human cell line derived from a oral sqamous carcinoma of the tongue. Tumor Res. 23: 46-57

16. Yokoi $T$, Hirata $S$, Nishimura $F$, Miyakawa $A$, Odajima $T$, Kohama $G$ and Mochizuki Y (1990) Some properties of a newly established human cell line derived from an oral squamous carcinoma. Tumor Res. 25: 93-103
17. Miyazaki A, Sato N, Takahashi S, Sasaki A, Kohama G, Yamaguchi A, Yagihashi A and Kikuchi K (1997) Cytotoxicity of histocompatibility leukocyte antigen-DR8-restricted CD4 killer T cells against human autologous squamous cell carcinoma. Jpn. J. Cancer Res. 88: 191-197

18. Bradford MM (1976) A rapid and sensitive method for the quantitation of microgram quantities of protein utilizing the principle of protein-dye binding. Anal. Biochem. 72: 248-254

19. Yokosawa N, Kubota T and Fujii N (1998) Poor induction of interferon-induced $2^{\prime}, 5^{\prime}$-oligoadenylate synthetase (2-5 AS) in cells persistently infected with mumps virus is caused by decrease of STAT- $1 \alpha$. Arch. Virol. 143: 1985-1992

20. Yokota S, Yanagi H, Yura T and Kubota $\mathrm{H}$ (2000) Upregulation of cytosolic chaperonin CCT subunits during recovery from chemical stress that causes accumulation of unfolded proteins. Eur. J. Biochem. 267: 1658-1664

21. Arata S, Hamaguchi S and Nose K (1995) Effects of the overexpression of the small heat shock protein, HSP27, on the sensitivity of human fibroblast cells exposed to oxidative stress. J. Cell Physiol. 163: 458-465

22. Arata S, Hamaguchi S and Nose K (1997) Inhibition of colony formation of NIH 3T3 cells by the expression of the small molecular weight heat shock protein HSP27: involvement of its phosphorylation and aggregation at the C-terminal region. J. Cell Physiol. 170: 19-26

23. Landry J, Lambert $\mathrm{H}$, Zhou M, Lavoie JN, Hickey E, Weber LA and Anderson CW (1992) Human HSP27 is phosphorylated at serines 78 and 82 by heat shock and mitogen-activated kinases that recognize the same amino acid motif as S6 kinase II. J. Biol. Chem. 267: 794-803

24. Hariya $Y$, Shirakawa S, Yonekura N, Yokosawa N, Kohama G and Fujii N (1999) Augmentation of verotoxin-induced cytotoxicity/apoptosis by interferon is repressed in cells persistently infected with mumps virus. J. Interferon Cytokine Res. 19: 479-485

25. Thornberry NA and Lazebnik Y (1998) Caspases: enemies within. Science 281: 1312-1316

26. Beere HM and Green DR (2001) Stress management - heat shock protein-70 and the regulation of apoptosis. Trends Cell Biol. 11: 6-10

27. Atkinson EA, Barry M, Darmon AJ, Shostak I, Turner PC, Moyer RW and Bleackley RC (1998) Cytotoxic T lymphocyte-assisted suicide. Caspase 3 activation is primarily the result of the direct action of granzyme B. J. Biol. Chem. 273: 21261-21266

28. Van de Craen M, Van den Brande I, Declercq W, Irmler M, Beyaert R, Tschopp $\mathrm{J}$, Fiers W and Vandenabeele P (1997) Cleavage of caspase family members by granzyme B: a comparative study in vitro. Eur. J. Immunol. 27: 1296-1299

29. Huot J, Roy G, Lambert H, Chretien P and Landry J (1991) Increased survival after treatments with anticancer agents of Chinese hamster cells expressing the human $\mathrm{Mr}$ 27,000 heat shock protein. Cancer Res. 51: 5245-5252

30. Oesterreich S, Weng CN, Qiu M, Hilsenbeck SG, Osborne CK and Fuqua SA (1993) The small heat shock protein hsp27 is correlated with growth and drug resistance in human breast cancer cell lines. Cancer Res. 53: 4443-4448

31. Garrido C, Ottavi P, Fromentin A, Hammann A, Arrigo AP, Chauffert B and Mehlen P (1997) HSP27 as a mediator of confluence-dependent resistance to cell death induced by anticancer drugs. Cancer Res. 57: 2661-2667

32. Rogalla T, Ehrnsperger M, Previllé X, Kotlyarov A, Lutsch G, Ducasse C, Paul C, Wieske M, Arrigo AP, Buchner J and Gaestel M (1999) Regulation of Hsp27 oligomerization, chaperone function, and protective activity against oxidative stress/tumor necrosis factor alpha by phosphorylation. J. Biol. Chem. 274: 18947-18956

33. Mehlen P, Hickey E, Weber LA and Arrigo AP (1997) Large unphosphorylated aggregates as the active form of hsp27 which controls intracellular reactive oxygen species and glutathione levels and generates a protection against TNF $\alpha$ in NIH-3T3-ras cells. Biochem. Biophys. Res. Commun. 241: 187-192

34. Kaur J, Kaur $J$ and Ralhan $R(2000)$ Induction of apoptosis by abrogation of HSP70 expression in human oral cancer cells. Int. J. Cancer 85: 1-5

35. Nylandsted J, Rohde M, Brand K, Bastholm L, Elling F and Jäättelä M (2000) Selective depletion of heat shock protein 70 (Hsp70) activates a tumor-specific death program that is independent of caspases and bypasses Bcl-2. Proc. Natl. Acad. Sci. USA 97: 7871-7876

36. Stokoe D, Engel K, Campbell DG, Cohen P and Gaestel M (1992) Identification of MAPKAP kinase 2 as a major enzyme responsible for the phosphorylation of the small mammalian heat shock proteins. FEBS Lett. 313: 307-313

37. Ludwig S, Engel K, Hoffmeyer A, Sithanandam G, Neufeld B, Palm D, Gaestel $M$ and Rapp UR (1996) 3pK, a novel mitogen-activated protein (MAP) kinase- 
activated protein kinase, is targeted by three MAP kinase pathways. Mol. Cell. Biol. 16: 6687-6697

38. Bruey J-M, Ducasse C, Bonniaud P, Ravagnan L, Susin SA, Diaz-Latoud C, Gurbuxani S, Arrigo A-P, Kroemer G, Solary E and Garrido C (2000) Hsp27 negatively regulates cell death by interacting with cytochrome $c$. Nat. Cell Biol. 2: 645-652

39. Benndorf R, Hayess K, Ryazantsev S, Wieske M, Behlke J and Lutsch G (1994) Phosphorylation and supramolecular organization of murine small heat shock protein HSP25 abolish its actin polymerization-inhibiting activity. J. Biol. Chem. 269: 20780-20784

40. Lavoie JN, Gingras-Breton G, Tanguay RM and Landry J (1993) Induction of Chinese hamster HSP27 gene expression in mouse cells confers resistance to heat shock ${ }^{*}$ HSP27 stabilization of the microfilament organization. J. Biol. Chem. 268: 3420-3429

41. Mehlen P, Schulze-Osthoff $K$ and Arrigo AP (1996) Small stress proteins as novel regulators of apoptosis. Heat shock protein 27 blocks Fas/APO-1- and staurosporine-induced cell death. J. Biol. Chem. 271: 16510-16514

42. Previllé X, Salvemini F, Giraud S, Chaufour S, Paul C, Stepien G, Ursini MV and Arrigo AP (1999) Mammalian small stress proteins protect against oxidative stress through their ability to increase glucose-6-phosphate dehydrogenase activity and by maintaining optimal cellular detoxifying machinery. Exp. Cell Res. 247: 61-78

43. Garrido C, Bruey JM, Fromentin A, Hammann A, Arrigo AP and Solary E (1999) HSP27 inhibits cytochrome $c$-dependent activation of procaspase-9. FASEB J. 13: 2061-2070

44. Pandey P, Farber R, Nakazawa A, Kumar S, Bharti A, Nalin C, Weichselbaum R, Kufe D and Kharbanda S (2000) Hsp27 functions as a negative regulator of cytochrome $c$-dependent activation of procaspase-3. Oncogene 19: 19751981

45. Charette SJ, Lavoie JN, Lambert $H$ and Landry J (2000) Inhibition of Daxxmediated apoptosis by heat shock protein 27. Mol. Cell. Biol. 20: 7602-7612

46. Gaestel M, Gotthardt R and Muller T (1993) Structure and organisation of a murine gene encoding small heat-shock protein Hsp25. Gene 128: 279-283

47. Jäättelä M (1999) Escaping cell death: survival proteins in cancer. Exp. Cell Res. 248: 30-43

48. Jäättelä M (1999) Heat shock proteins as cellular lifeguards. Ann. Med. 31 261-271

49. Arrigo AP (2000) sHsp as novel regulators of programmed cell death and tumorigenicity. Pathol. Biol. 48: 280-288 